\title{
Erratum to: Oral appliance titration in patients with obstructive sleep apnea induces the appearance of periodic limb movements
}

\author{
Melanie L. Guerrero • Daniel Kim • Tracy L. Rupp • \\ Thomas J. Balkin
}

Published online: 10 August 2010

(C) Springer-Verlag 2010

\section{Erratum to: Sleep Breath}

DOI 10.1007/s11325-009-0321-z

Unfortunately, there are some errors in the article which need to be corrected as follows:

1. Affiliation of corresponding author should read as follows:

Department of Behavioral Biology, Walter Reed Army Institute of Research

2. Ref\#17 has been incorrectly cited and should read as follows:

Kristo DA, Lettieri CJ, Andrada T, Taylor Y, Eliasson AH (2005) Silent upper airway resistance syndrome: prevalence in a mixed military population. CHEST 127(5):1654-1657

The online version of the original article can be found at http://dx.doi. org/10.1007/s11325-009-0321-z.

\footnotetext{
M. L. Guerrero $(\bowtie) \cdot$ T. L. Rupp · T. J. Balkin

Department of Behavioral Biology,

Walter Reed Army Institute of Research,

503 Robert Grant Avenue,

Silver Spring, MD 20910, USA

e-mail: Melanie.guerrero@us.army.mil

D. Kim

Department of Medicine, Pulmonary, Critical Care, and Sleep Service, Walter Reed Army Medical Center,

Washington, DC 20307, USA
}

3. Abstract second paragraph called Design should read: This is a retrospective, observational study set in a sixbed sleep center in an academic, military referral hospital.

4. Abstract third paragraph called Patients and Methods should read: Patients with OSA $(n=21 ; 15$ men and six women; mean age, 43 years; and age range, 25 to 53 years) treated with OA during a 1-year period were analyzed.

5. Abstract fourth paragraph called Results should read: Twenty-one patients were included in the analysis.

6. Fourth paragraph of section entitled Background (second page): should read-"We performed a retrospective, observational study to determine the incidence of PLM in patients treated with oral appliance therapy."

7. First paragraph of section entitled Materials and Methods (second page) should read: "The study was a retrospective, observational study performed in the Sleep Disorders Center of a single center, academic, military referral hospital which serves military service members, retired members, and civilian dependents."

8. Second subtitle of section Materials and Methods (second page) should read: Subject inclusion.

9. Fifth paragraph of section Materials and Methods (third page) should read: Patients were included in the analysis if a diagnostic polysomnography revealed an apnea hypopnea index (AHI) greater than 5 per hour. 